\title{
APLIKASI PERLAKUAN PENDAHULUAN PULSED ELECTRIC FIELD (PEF) PADA EKSTRAKSI TANIN BIJI PINANG (Areca catechu) (KAJIAN FREKUENSI DAN WAKTU PEF)
}

\section{PULSED ELECTRIC FIELD (PEF) PRETREATMENT APPLICATION AT ARECA (ARECA CATECHU) NUT-TANNINS EXTRACTION (STUDY OF PEF FREQUENCY AND TIME)}

\author{
Nur Lailatul Rahmah, Sukardi, dan Irwina Nova Dila \\ Jurusan Teknologi Industri Pertanian, Fakultas Teknologi Pertanian, Universitas Brawijaya \\ Jl. Veteran Malang 65145, Malang, Jawa Timur \\ Email: nur_laila@ub.ac.id
}

Makalah: Diterima 1 September 2018; Diperbaiki 2 Januari 2019; Disetujui 15 Januari 2019

\begin{abstract}
Areca catechu contains tannins compounds acting as antioxidants. Extraction process is required to obtain these compounds from areca nut. Pretreatment before extraction using Pulsed Electric Field (PEF) has shown improvement of yield as well as the quality of antioxidant extracts compared with control. The experimental design of this research was Factorial Random Design with two factors. The first factor was frequency of PEF with three levels of $1,1.5$, and $2 \mathrm{kHz}$ and the second factor was PEF application time with three levels of 20, 25, and 30 seconds. The extract of areca seed from PEF extraction with combination of frequency and time of PEF using magnetic field $450 \mathrm{v} / \mathrm{cm}$ did not provide significanty different yield and quality. The selection of best treatment was based on the economic aspects and analysis of variance, since there was no significant difference between each parameter and treatment. The best frequency and duration of PEF on yield and antioxidant quality of areca nut extract were $1 \mathrm{kHz}$ and 20 second with a yield of 5.6\%; moisture content of 7.78\%; IC50 value of 277,56 ppm; and tannins content of $442.36 \mathrm{mg}$ GAE/g. FTIR spectrophotometric analysis results showed that the resulting absorption has a functional group that supports the presence of tannins.
\end{abstract}

Keywords: fresh areca nut, electroporation, electrical pulse

\section{ABSTRAK}

Biji pinang (Areca catechu) memiliki kandungan senyawa tanin yang berfungsi sebagai antioksidan. Untuk mendapatkan senyawa tersebut dibutuhkan proses ekstraksi biji pinang. Perlakuan pendahuluan sebelum ekstraksi menggunakan Pulsed Electric Field (PEF) terbukti dapat meningkatkan rendemen dan kualitas antioksidan ekstrak dibandingkan kontrol. Oleh karena itu, dilakukan penelitian ekstraksi biji pinang dengan perlakuan pendahuluan PEF menggunakan variasi frekuensi dan waktu aplikasi PEF dengan medan listrik sebesar $450 \mathrm{v} / \mathrm{cm}$. Rancangan percobaan pada penelitian ini adalah rancangan acak kelompok faktorial dengan dua faktor. Faktor pertama adalah frekuensi PEF dengan tiga level yaitu 1; 1,5; dan $2 \mathrm{kHz}$ dan faktor kedua adalah waktu aplikasi PEF dengan tiga level yaitu 20, 25 dan 30 detik. Ekstrak biji pinang hasil ekstraksi dengan perlakuan pendahuluan PEF dengan kombinasi frekuensi dan lama waktu PEF tidak menghasilkan rendemen dan kualitas yang berbeda secara signifikan. Pemilihan perlakuan terbaik didasarkan atas aspek ekonomi dari perlakuan dan telaah ANOVA karena setiap parameter dan setiap perlakuan tidak berbeda signifikan. Frekuensi dan lama waktu PEF terbaik terhadap rendemen dan kualitas antioksidan ekstrak biji pinang adalah $1 \mathrm{kHz}$ dan 20 detik dengan nilai rendemen 5,6\%; kadar air 7,78\%; nilai IC50 277,56 ppm; dan kadar tanin 442,36 mg GAE/g. Hasil analisis spektrofotometri FTIR menunjukkan bahwa serapan yang dihasilkan memiliki gugus fungsi yang menunjang keberadaan tanin.

Kata kunci: biji pinang segar, elektroporasi, pulsa listrik

\section{PENDAHULUAN}

Indonesia merupakan negara agraris yang mempunyai potensi besar, antara lain dari hasil pertanian, perkebunan dan hasil hutan. Salah satu hasil perkebunan yang memilki manfaat untuk pengobatan adalah tanaman pinang. Menurut data BPS (Badan Pusat Statistik) 2017 produksi perkebunan tanaman pinang pada tahun 2012-2015 meningkat dari tahun ke tahun, yaitu berturut-turut 42,0; 42,8; 47,0 dan 47,1 ribu ton. Menurut Peng et al. (2015) biji pinang memiliki 59 senyawa yang dapat diisolasi dan diidentifikasi yang mayoritas senyawanya adalah alkaloid tipe piridin dan tanin terkondensasi sebagai pencirinya. Ekstrak air maupun methanol dari biji pinang memiliki aktivitas antioksidan dan total fenolik yang lebih tinggi daripada ekstrak akarnya (Hamsar et al., 2011). Untuk memperoleh kandungan antioksidan pada biji pinang tersebut diperlukan proses ekstraksi.

Ekstraksi yang sudah dilakukan pada biji pinang diantaranya menggunakan metode maserasi dan sokletasi (Bhandare et al., 2010; Hamsar et al., 2011; Mamonto et al., 2014). Rendemen ekstrak biji 
pinang dengan metode sokletasi dan pelarut methanol yang dihasilkan pada penelitian Mamonto et al. (2014) sangat kecil yaitu 3,87\% dan aktivitas antioksidan dengan nilai ekuivalen asam galat sebesar 59,33 eq GAE/g. Kecilnya rendemen dan aktivitas antioksidan pada penelitian tersebut diduga kurang efektifnya proses ekstraksi tanpa adanya perlakuan pendahuluan pada simplisia. Lain halnya dengan penelitian Rahmah et al. (2017) yang melakukan perlakuan pendahuluan ekstraksi menggunakan teknik Pulsed Electric Field (PEF= medan listrik berpulsa/berdenyut) yang menghasilkan rendemen ekstrak biji pinang sebesar 4,63\% dan nilai kadar tanin sebesar 507,42 mg $\mathrm{GAE} / \mathrm{g}$.

PEF disebut juga dengan istilah elektroporasi yaitu pemberian tegangan listrik pada sel, agar sel mengalami kerusakan dinding sel tanpa merusak komponen bioktif yang ada di dalam sel (Sukardi, 2016), seperti senyawa antioksidan dan metabolit sekunder. Pada biji tanaman palma seperti Palma Swamp (Mauritia flexuosa) tersusun atas sel endosperma. Vakuola pada sel endosperma terakumulasi di dalamnya senyawa fenolik, alkaloid, dan terpenoid (Silva et al., 2014). Sama halnya dengan biji pinang, diduga senyawa antioksidan dan metabolit sekundernya juga tersimpan dalam vakuola sel endosperma.

Pada aplikasi PEF, polarisasi membran sel menghasilkan dispersi antara $1 \mathrm{kHz}$ dan $10 \mathrm{MHz}$ tergantung pada ukuran sel dan konduktivitas elektrolit sekitarnya. Dispersi diartikan sebagai pergerakan ion-ion dalam sel yang berpengaruh nantinya pada elektroporasi sel (Pliquet, 2010; Donsi et al., 2010). Modifikasi pada frekuensi dengan menggunakan medan listrik yang sama diduga akan berpengaruh pada "yield" ekstrak. Waktu sangat berpengaruh pada medan listrik yang diberikan pada bahan. Peningkatan waktu menghasilkan peningkatan rendemen ekstrak, namun demikian waktu yang terlalu lama dapat menurunkan rendemen karena ketahanan membrane sel berkurang (Sukardi, 2016; Janositz, 2010). Oleh karena itu, perlu dilakukan penelitian mengenai aplikasi PEF pada ekstraksi antioksidan biji pinang untuk mengetahui frekuensi dan waktu aplikasi PEF yang tepat untuk menghasilkan kualitas ekstrak antioksidan yang lebih baik.

\section{BAHAN DAN METODE}

\section{Bahan dan Alat \\ Bahan}

Bahan utama yang digunakan dalam penelitian ini adalah biji pinang (Areca catechu) muda hingga setengah tua (warna hijau hingga oranye) yang diperoleh dari Kota Malang, Jawa Timur. Bahan dalam analisis laboratorium antara lain aquades, etanol $96 \%$, asam galat, $\mathrm{Na}_{2} \mathrm{CO}_{3}$, Folin Denis, dan DPPH, lakban, dan kertas label.

\section{Alat}

Alat-alat yang digunakan dalam proses pembuatan ekstrak kasar biji pinang adalah Generator Pulsed Electric Field (Gambar 1) yang dilengkapi dengan chamber tabung plastik transparan. Spesifikasi Generator PEF: input voltase $150 \mathrm{w}$, luaran medan listrik 0,5 sd $5000 \mathrm{v} / \mathrm{cm}$, frekuensi $10 \mathrm{~Hz}$ sd $10 \mathrm{kHz}$, lebar pulsa $1 \mathrm{sd} 200 \mathrm{mS}$, waktu paparan 1 detik sd 2 jam, output tegangan bipolar dan monopolar, diameter chamber PEF 11,5 $\mathrm{cm}$ dan tinggi $25 \mathrm{~cm}$ ), timbangan digital (Denver Instrumen M-310), labu ukur $100 \mathrm{~mL}$ (Pyrex), sendok, gelas beaker $600 \mathrm{~mL}$ (Pyrex), kertas saring, corong, loyang, kulkas (Toshiba), wadah kedap cahaya, botol kecil, pisau, oven dan aluminium foil.

Alat yang digunakan dalam analisis adalah timbangan digital (Denver Instrumen M-310), gelas beaker 200 (Pyrex), pipet volume (HG), bola hisap (Merienfiel), tabung reaksi (pyrex), plastik, rak tabung kayu, aluminium foil, kuvet, vortex, spektrofotometer UV VIS (20 D Plus), FTIR spectrophotometer (8400S/Shimadzu), oven, desikator, cawan petri dan labu ukur $100 \mathrm{~mL}$ (Pyrex).

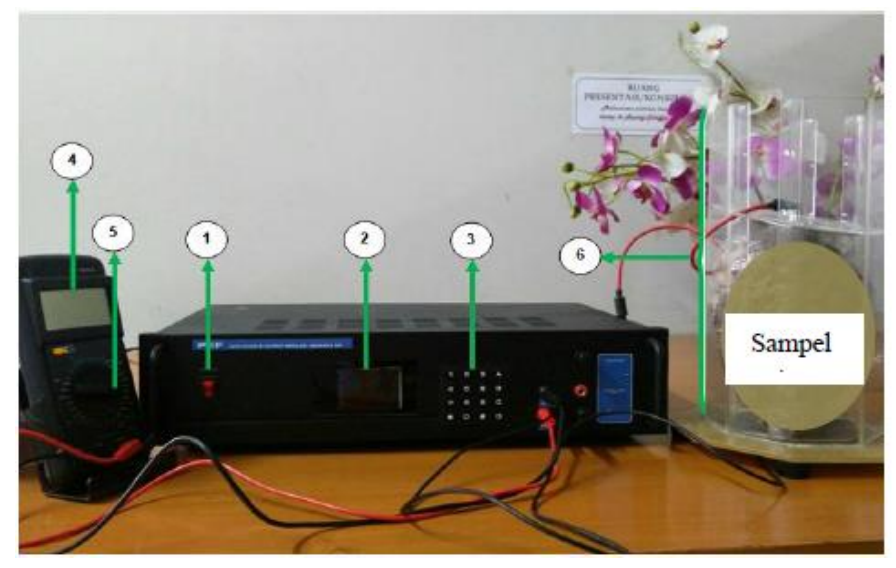

\section{Keterangan:}

1. Tombol on off

2. Layar penunjuk frekuensi, waktu paparan, dan lebar pulsa

3. Tombol pengatur frekuensi, waktu paparan, dan start

4. Layar penunjuk tegangan

5. Pengatur tegangan

6. Jarak anoda katoda pada ruang perlakuan (Treatment Chamber)

Gambar 1. Generator PEF 


\section{Penentuan Rancangan Percobaan}

Penelitian ini menggunakan metode Rancangan Acak Kelompok (RAK) faktorial dengan 2 faktor, faktor 1 adalah faktor frekuensi pulsa PEF yang mempunyai 3 level, yaitu : $1 \mathrm{kHz}\left(\mathrm{F}_{1}\right) ; 1,5 \mathrm{kHz}$ $\left(\mathrm{F}_{2}\right)$ dan $2 \mathrm{kHz}\left(\mathrm{F}_{3}\right)$ dan faktor 2 adalah lama waktu PEF yang mempunyai 3 level, yaitu : 20 detik $\left(\mathrm{T}_{1}\right)$ 25 detik $\left(\mathrm{T}_{2}\right)$; dan 30 detik $\left(\mathrm{T}_{3}\right)$ sehingga terdapat 9 kombinasi perlakuan. Pada penelitian yang menjadi kelompok adalah ulangan. Masing-masing perlakuan diulang sebanyak 3 kali sehingga didapatkan 27 satuan percobaan. Tegangan yang digunakan adalah $4,5 \mathrm{kV}$, jarak antara katoda dan anoda $10 \mathrm{~cm}$ dan medan listrik $450 \mathrm{v} / \mathrm{cm}$.

\section{Pelaksanaan Penelitian}

Penelitian ini dibagi menjadi dua tahapan, yaitu proses ekstraksi dengan menggunakan perlakuan pendahuluan PEF dan kontrol (tanpa PEF). Adapun prosedur penelitiannya dijelaskan sebagai berikut:

\section{Proses Perlakuan Pendahuluan Biji Pinang dengan PEF}

Langkah-langkah perlakuan pendahuluan biji pinang dengan PEF adalah sebagai berikut: buah pinang disortasi yang bertujuan untuk menghilangkan kotoran atau buah yang busuk. Buah pinang selanjutnya dikupas dan diambil bijinya. Biji pinang kemudian dihaluskan untuk memperluas permukaan dan ditimbang sebanyak $50 \mathrm{~g}$. Biji pinang dimasukkan kedalam chamber pada alat generator PEF kemudian diberikan kejutan listrik dengan tegangan $4,5 \mathrm{kV} / \mathrm{cm}$, jarak antara katoda dan anoda $10 \mathrm{~cm}$, medan listrik $450 \mathrm{v} / \mathrm{cm}$ dan frekuensi masing-masing 1; 1,5 dan $2 \mathrm{kHz}$ pada waktu 20, 25, dan 30 detik. Campuran bahan dan pelarut [1:4 $(\mathrm{b} / \mathrm{v})$ ] selanjutnya dimaserasi kinetik dengan pemanasan menggunakan water bath shaker selama 120 menit pada suhu $60^{\circ} \mathrm{C}$. Tahap selanjutnya dilakukan penyaringan dengan kertas saring untuk mendapatkan filtrat biji pinang, dioven selama 24 jam pada suhu $59^{\circ} \mathrm{C}$ dan dilakukan perhitungan rendemen analisis kadar air, aktivitas antioksidan dan kadar tanin.

\section{Proses Perlakuan Kontrol Tanpa Perlakuan Pendahuluan PEF \\ Langkah-langkah ekstraksi tanpa perlakuan pendahuluan adalah sebagai berikut: buah pinang disortasi untuk menghilangkan kotoran atau buah yang busuk. Buah pinang selanjutnya dikupas diambil bijinya. Biji pinang kemudian dihaluskan dengan blender untuk memperluas permukaan dan ditimbang sebanyak $50 \mathrm{~g}$ (tanpa perlakuan pendahuluan PEF). Campuran bahan dan pelarut [1:4 (b/v)] selanjutnya di maserasi kinetic dengan pemanasan menggunakan water bath shaker selama 120 menit pada suhu $60^{\circ} \mathrm{C}$. selanjutnya dilakukan penyaringan dengan kertas saring untuk}

mendapatkan filtrat biji pinang, dioven selama 24 jam pada suhu $59^{\circ} \mathrm{C}$ dan dilakukan perhitungan rendemen analisa kadar air, aktivitas antioksidan dan kadar tanin.

\section{Pengujian dan Analisis}

Pengujian dan analisis dilakukan pada ekstrak biji pinang. Pengujian yang dilakukan adalah rendemen, aktivitas antioksidan dengan reagen DPPH, dan kadar air serta dan uji tanin. Untuk mengetahui perbedaan hasil antara yang dilakukan PEF dan tidak, maka hasil terbaik dengan kontrol dilakukan uji FTIR.

\section{Perhitungan Rendemen}

Analisa rendemen untuk mengetahui seberapa besar persentase yang dihasilkan.

- Bahan baku ditimbang sebelum dilakukan pengolahan

- Kemudian dibandingkan dengan produk yang dihasilkan

$$
\text { Rendemen }(\%)=\frac{\text { Berat produk jadi }}{\text { Berat bahan baku }} \times 100 \%
$$

\section{Analisa Aktivitas Antioksidan Metode DPPH (diukur sebagai IC50) (Rahmah et al., 2017)}

Pembuatan larutan ekstrak 1000 ppm lalu diencerkan menjadi 200, 400, dan 600 ppm. Kemudian diukur absorbansi dengan spektrofotometer dengan menambahkan $1 \mathrm{~mL}$ ekstrak dengan konsentrasi 200, 400, dan 600 ppm dengan metanol sebanyak $7 \mathrm{~mL}$. Selanjutnya ditambahkan larutan DPPH sebanyak $2 \mathrm{~mL}$ dengan konsentrasi 0,2 mM. Kemudian divortex selama 2 menit dan didiamkan selama 30 menit sebelum dianalisis. Lalu diambil larutan sebanyak $1 \mathrm{~mL}$ dan diukur absorbansinya pada $K=517 \mathrm{~nm}$. Kontrol yang digunakan adalah larutan DPPH dan metanol. Nilai absorbansi masing-masing konsentrasi pada setiap sampel dibuat persamaan regresi liniernya $(\mathrm{y}=$ $\mathrm{a}+\mathrm{bx}$ ) dengan $\mathrm{x}$ (konsentrasi) dan y (absorbansi untuk memperoleh nilai intersep (a) dan slope (b).

$$
\mathrm{IC50}=\frac{(\text { absorbansi kontrol } / 2)-\mathrm{a}}{\mathrm{b}}
$$

\section{Analisa Kadar Tanin (Tambe and Rajendra, 2014)}

Pembuatan larutan stok asam galat 100 ppm, kemudian diencerkan menjadi 80, 60, 40 dan 20 ppm. Selanjutnya dibuat kurva standar asam galat dengan memasukkan $0,1 \mathrm{~mL}$ larutan asam galat berbagai konsentrasi kedalam labu takar $10 \mathrm{~mL}$, ditambahkan 7,5 mL akuades, $0,5 \mathrm{~mL}$ reagen Folin 
Ciocalteu, dan $1 \mathrm{~mL} \mathrm{Na}_{2} \mathrm{CO}_{3} \quad 35 \%$. Kemudian tambahkan akuades sampai tanda batas dan simpan pada suhu ruang. Absorbansi larutan diukur pada $725 \mathrm{~nm}$. Selanjutnya dibuat kurva standar dengan sumbu $\mathrm{x}$ konsentrasi asam galat dan sumbu $\mathrm{y}$ absorbansi. Blanko adalah $8,5 \mathrm{~mL}$ akuades, $0,5 \mathrm{ml}$ reagen Folin Ciocalteu, dan $1 \mathrm{~mL} \mathrm{Na} \mathrm{CO}_{3} 35 \%$. Untuk mengukur kadar tanin sampel, dilakukan prosedur dengan cara yang sama seperti pembuatan kurva standar, namun asam galat diganti dengan sampel 0,1 mL $1000 \mathrm{ppm}$.

\section{Pengolahan dan Analisis Data}

Analisa data diolah menggunakan ANOVA dengan bantuan software SPSS. Hal ini untuk mengetahui beda nyata atau tidak pada setiap faktor, apabila hasil dari analisa ragam menunjukkan beda nyata pada masing-masing faktor maka dilakukan uji lanjut, apabila hasil dari analisa ragam menunjukkan adanya interaksi antar faktor perlakuan maka akan dilanjutkan dengan uji DMRT 5\%, sedangkan apabila tidak ada interaksi antar faktor perlakuan maka dilanjutkan uji BNT 5\% pada masing-masing faktor.

\section{Pemilihan Perlakuan Terbaik}

Penentuan perlakuan terbaik pada penelitian ini berdasarkan hasil ANOVA dari nilai kadar air dan $\mathrm{IC}_{50}$ yang paling rendah serta hasil rendemen dan kadar tanin yang paling tinggi dari semua perlakuan.

\section{HASIL DAN PEMBAHASAN}

\section{Rendemen}

Hasil dari rendemen ekstrak biji pinang segar dengan perhitungan wet basis pada penelitian ini disajikan dalam Gambar 2. Rendemen ekstrak biji pinang segar adalah persentase crude ekstrak yang dihasilkan dari proses ekstraksi serbuk biji pinang. Bentuk akhir dari ekstrak biji pinang pada penelitian ini berupa padatan. Hasil ANOVA menggunakan SPSS dengan tingkat kepercayaan $95 \%(\alpha=0,05)$ menunjukkan bahwa interaksi dan masing-masing faktor frekuensi dan waktu PEF tidak memberikan pengaruh yang signifikan terhadap rendemen ekstrak biji pinang segar. Hal ini ditunjukkan dengan nilai sig lebih besar dari 0,05.

Tidak adanya pengaruh kedua faktor terhadap nilai rendemen menunjukkan bahwa rentang frekuensi dan waktu terlalu dekat sehingga menghasilkan pengaruh yang sama pada setiap perlakuan. Diduga bahwa variasi waktu paparan pulsa listrik belum sepenuhnya membuka pori-pori sel sehingga ekstrak yang dihasilkan belum menunjukkan perbedaan rendemen pada berbagai frekuensi. Sesuai dengan uji t antara perlakuan dengan kontrol juga tidak menunjukkan perbedaan signifikan. Hal ini menunjukkan bahwa rendemen ekstrak antara yang mendapat perlakuan pendahuluan dan tidak mendapatkan perlakuan pendahuluan memiliki hasil yang sama.

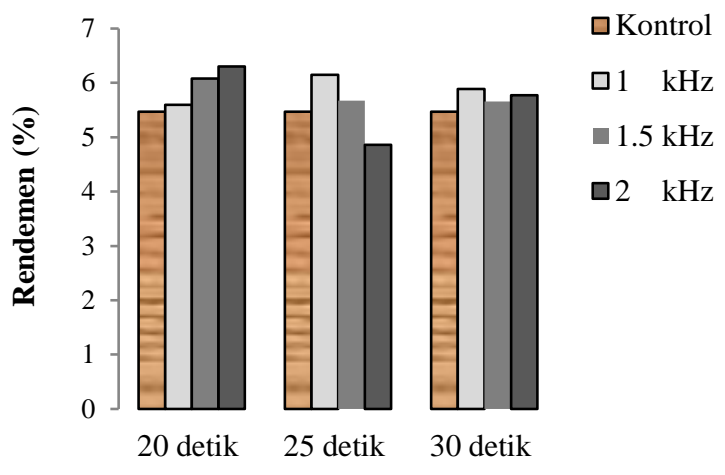

Gambar 2. Grafik hubungan rendemen dengan lama waktu paparan PEF

Penerapan PEF mampu membentuk lubang pori pada dinding sel sehingga minyak di dalam sel keluar (Sukardi et al., 2016). Adanya kejutan listrik tersebut menyebabkan modifikasi pada permukaan sel tanaman sehingga kemampuan difusi pada proses ekstraksi dapat meningkat. Akan tetapi, berdasarkan uji t pada data yang disajikan oleh Gambar 2, antara kontrol (tanpa PEF) dengan perlakuan yang menggunakan perlakuan pendahuluan PEF, tidak menunjukkan perbedaan yang signifikan pada rendemennya. Hal tersebut menunjukkan bahwa aplikasi lama waktu kejutan listrik dengan frekuensi 1; 1,5 dan $2 \mathrm{kHz}$ dengan lama waktu 20; 25 dan 30 detik diduga belum mampu menghasilkan pori pada dinding sel biji pinang segar dan belum ada modifikasi pada permukaan sel tanaman. Dengan demikian, antara perlakuan yang diberi treatment PEF dan kontrol diduga memiliki laju difusi yang sama (perpindahan bahan aktif ke dalam pelarut akuades) sehingga menghasilkan rendemen yang sama.

Biji pinang segar yang hanya dihaluskan memiliki kadar air yang tinggi dan nilai medan listrik dalam sel lebih besar daripada aplikasi PEF (450 v/cm) yang diterapkan pada bahan sehingga tidak menyebabkan pergerakan elektron yang berarti (Jiahui et al., 2009). Berbeda pula dengan jenis bahan lain seperti pada bunga melati segar, dengan PEF yang menggunakan medan listrik $100 \mathrm{v} / \mathrm{cm}$ telah dihasilkan pori pada dinding selnya yang ditunjukkan dengan hasil SEM (Sukardi et al., 2016). Hal tersebut menunjukkan bahwa jenis bahan juga mempengaruhi elektroporasi pada dinding sel tanaman.

\section{Kadar Air}

Hasil dari kadar air ekstrak pada penelitian ini disajikan dalam Gambar 3. Hasil ANOVA dengan tingkat kepercayaan 95\% $(\alpha=0,05)$ menunjukkan bahwa interaksi dan masing-masing faktor frekuensi dan waktu PEF tidak memberikan pengaruh yang signifikan terhadap kadar air ekstrak. 
Hal ini ditunjukkan dengan nilai sig lebih besar dari 0,05 .

Tidak adanya pengaruh kedua faktor terhadap nilai kadar air menunjukkan bahwa rentang frekuensi dan waktu terlalu dekat sehingga menghasilkan pengaruh yang sama pada setiap perlakuan. Diduga bahwa variasi waktu paparan pulsa listrik belum sepenuhnya membuka pori-pori sel sehingga ekstrak yang dihasilkan belum menunjukkan perbedaan pada berbagai frekuensi. Sesuai dengan uji t antara perlakuan dengan kontrol juga tidak menunjukkan perbedaan signifikan. Hal ini menunjukkan bahwa kadar air ekstrak antara yang mendapat perlakuan pendahuluan dan tidak mendapatkan perlakuan pendahuluan memiliki hasil yang sama. Menurut Yildiz (2010), pada saat pengeringan bahan pangan, hanya air bebas dan air yang terperangkap yang dapat mudah diuapkan, sedangkan air terikat tidak dapat dengan mudah diuapkan. Hal ini dikarenakan air terikat adalah lapisan molekul air yang paling dekat dengan zat terlarut dan konstituen tak berair lainnya dan lebih terikat secara struktural daripada air yang bebas atau terperangkap menghambat mobilitas. Adanya perlakuan pendahuluan PEF maupun tanpa PEF, tidak mempengaruhi energi pemutusan ikatan air dengan matriks pada proses pengeringan ekstrak (suhu $59-60^{\circ} \mathrm{C}$ ) sehingga jumlah air dalam ekstrak sama. Hubungan kadar air dengan lama waktu PEF disajikan pada Gambar 3.

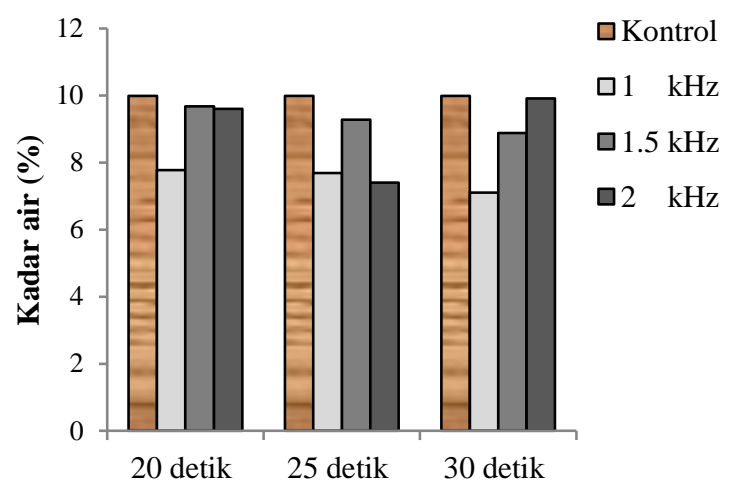

Gambar 3. Grafik hubungan kadar air dengan lama waktu PEF

Berdasarkan uji t, antara kontrol (tanpa PEF) dengan perlakuan yang menggunakan perlakuan pendahuluan PEF, tidak menunjukkan perbedaan yang signifikan pada nilai kadar airnya. Kadar air merupakan jumlah air yang terdapat di dalam ekstrak. Hal tersebut menunjukkan bahwa aplikasi lama waktu kejutan listrik dengan frekuensi 1; 1,5 dan $2 \mathrm{kHz}$ dengan lama waktu 20; 25 dan 30 detik belum mampu membentuk pori pada dinding sel biji pinang dan belum ada modifikasi pada permukaan sel tanaman sehingga jumlah zat yang berdifusi ke dalam pelarut akuades memiliki jumlah yang sama dan mengakibatkan kekentalan larutan ekstrak sama. Dengan demikian, melalui proses pengeringan yang sama, maka jumlah air (kadar air) yang terkandung pada ekstrak yang diberi perlakuan pendahuluan PEF dan tidak diberi perlakuan PEF sama.

\section{Aktivitas Antioksidan (IC50)}

Aktivitas antioksidan (IC50) adalah konsentrasi DPPH sisa (ppm) yang tidak bereaksi dengan senyawa antioksidan ekstrak biji pinang dari proses ekstraksi biji pinang segar. Hasil IC50 ekstrak biji pinang pada penelitian ini disajikan dalam Gambar 4. Hasil ANOVA dengan tingkat kepercayaan 95\% $(\alpha=0,05)$ menunjukkan bahwa interaksi dan masing-masing faktor frekuensi dan waktu PEF tidak memberikan pengaruh yang signifikan terhadap aktivitas antioksidan ekstrak biji pinang. Hal ini ditunjukkan dengan nilai sig lebih besar dari 0,05 .

Tidak adanya pengaruh kedua faktor terhadap nilai aktivitas antioksidan ekstrak biji pinang menunjukkan bahwa variasi perlakuan perlu dimodifikasi kembali. Diduga bahwa variasi waktu paparan pulsa listrik belum sepenuhnya membuka pori-pori sel sehingga ekstrak biji pinang yang dihasilkan belum menunjukkan perbedaan aktivitas antioksidan pada berbagai frekuensi.

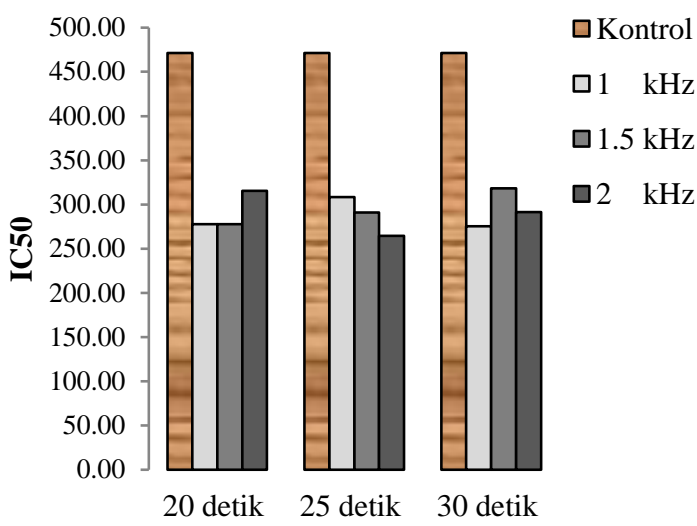

Gambar 4. Grafik hubungan aktivitas IC50 dengan lama waktu PEF

Berdasarkan uji t, terlihat bahwa nilai IC50 ekstrak biji pinang dengan perlakuan pendahuluan PEF dan tanpa PEF menghasilkan nilai IC50 yang berbeda. Nilai IC50 ekstrak yang menggunakan perlakuan pendahuluan PEF lebih kecil dibandingkan tanpa menggunakan PEF. Namun demikian, keduanya memiliki aktifitas antioksidan dalam kategori lemah yaitu antara 250-500 ppm (Jun et al., 2003). Diduga bahwa waktu pemaparan kejut listrik terlalu singkat, sehingga belum semua senyawa aktif antioksidan dalam pinang dapat berdifusi ke dalam pelarut akuades. Peningkatan waktu menghasilkan peningkatan rendemen ekstrak, namun demikian waktu yang terlalu lama dapat menurunkan rendemen karena ketahanan membrane sel berkurang (Sukardi, 2016; Janositz, 2010). 
Aplikasi frekuensi PEF baik pada kisaran $10 \mathrm{kHz}-$ $1 \mathrm{MHz}$. Polarisasi membran sel menghasilkan dispersi antara $1 \mathrm{kHz}$ dan $10 \mathrm{MHz}$ tergantung pada ukuran sel dan konduktivitas elektrolit sekitarnya. Dispersi diartikan sebagai pergerakan ion-ion dalam sel yang berpengaruh pada elektroporasi sel (Pliquet, 2010; Donsi et al., 2010).

\section{Kadar Tanin}

Hasil dari kadar tanin pada penelitian ini disajikan dalam Gambar 5. Kadar tanin adalah jumlah mg tanin ekivalen terhadap asam galat setiap gramnya (mg GAE / g) yang dihasilkan dari proses ekstraksi serbuk biji pinang. Hasil analisis sidik ragam (ANOVA) dengan tingkat kepercayaan $95 \%$ $(\alpha=0,05)$ didapatkan bahwa interaksi dan masingmasing faktor frekuensi dan waktu PEF tidak memberikan pengaruh yang signifikan terhadap kadar tanin. Hal ini ditunjukkan dengan nilai sig lebih besar dari 0,05.

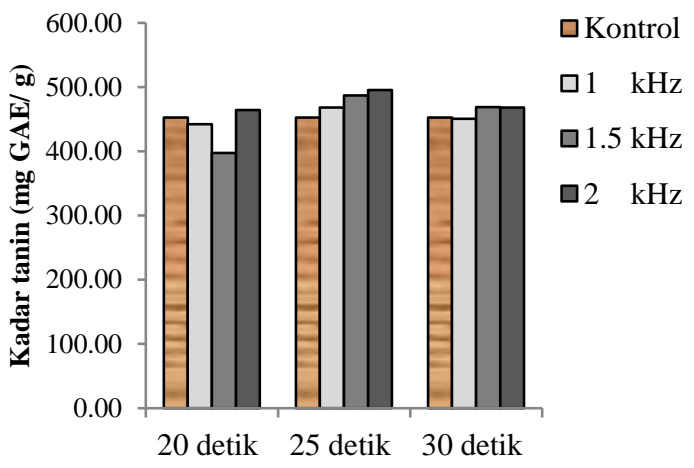

Gambar 5. Grafik hubungan kadar tanin dengan lama waktu paparan PEF

Tidak adanya pengaruh kedua faktor terhadap nilai kadar tanin menunjukkan bahwa variasi perlakuan perlu dimodifikasi kembali. Diduga bahwa variasi waktu paparan pulsa listrik belum sepenuhnya membuka pori-pori sel sehingga tanin yang dihasilkan belum menunjukkan perbedaan pada berbagai frekuensi. Berdasarkan uji $\mathrm{t}$, kadar tanin antara yang diberi treatment PEF dan tidak diberi perlakuan pendahuluan PEF tidak menunjukkan perbedaan yang signifikan. Proses tersebut diduga memiliki laju yang sama pada proses perpindahan bahan aktif tanin ke dalam pelarut akuades sehingga menghasilkan kadar tanin yang sama. Pada penelitian ini, variasi waktu paparan pulsa listrik yang terlalu cepat diduga belum mampu menghasilkan pori pada dinding sel sehingga bahan aktif tanin yang berdifusi ke dalam pelarut akuades jumlahnya sama dengan perlakuan tanpa PEF. Begitu pula variasi frekuensi yang diaplikasikan pada pinang segar belum mampu menghasilkan polarisasi membrane. Diduga karena bahan biji pinang segar yang diberi kejut listrik masih memiliki kadar air yang cukup tinggi, maka diperlukan frekuensi yang lebih besar untuk membuka pori dinding sel pinang. Hal tersebut diduga adanya gangguan molekul air pada bahan pinang segar sehingga dapat menurunkan konduktivitas elektrolit di sekitarnya. Menurut Pliquet (2010) dan Donsi et al. (2010) polarisasi membran sel menghasilkan dispersi antara $1 \mathrm{kHz}$ dan $10 \mathrm{MHz}$ tergantung pada ukuran sel dan konduktivitas elektrolit sekitarnya. Dispersi diartikan sebagai pergerakan ion-ion dalam sel yang berpengaruh pada elektroporasi sel.

\section{Pemilihan perlakuan terbaik}

Berdasarkan hasil ANOVA, setiap parameter dan setiap perlakuan tidak berbeda signifikan. Oleh karena itu, frekuensi dan lama waktu PEF yang paling rendah yang menjadi perlakuan terbaik. Frekuensi dan lama waktu PEF terbaik terhadap rendemen dan kualitas antioksidan ekstrak biji pinang adalah $1 \mathrm{kHz}$ dan 20 detik dengan nilai rendemen 5,6\%; kadar air 7,78\%; nilai IC50 277,56 ppm; dan kadar tanin 442,36 mg GAE / g.

\section{Hasil Analisis Spektrofotometri FTIR}

Hasil analisis FTIR perlakuan terbaik yang dihasilkan dari perlakuan pendahuluan PEF dengan frekuensi $1 \mathrm{kHz}$ dan waktu PEF 20 detik dengan nilai rendemen 5,6\%; kadar air 7,78\%; nilai IC50 277,56 ppm; dan kadar tanin 442,36 mg GAE/g ditunjukkan pada Tabel 1. Berdasarkan Tabel 1, nilai bilangan gelombang $\left(\mathrm{cm}^{-1}\right)$ pada band menunjukkan nilai remark yang sama dengan hasil tanin kulit pohon Schinopsis quebracho Colorado (PantojaCastro dan Horacio, 2012) berdasarkan interpretasi. Hasil spektra IR ekstrak kontrol (Gambar 6) dan perlakuan terbaik (Gambar 7) juga menunjukkan band yang sama. Gugus -OH (alkohol, fenol) ditunjukkan pada bilangan gelombang 3383,67; 3231,31 untuk kontrol dan 3264,09 $\mathrm{cm}^{-1}$ untuk perlakuan terbaik. Gugus C-H dan C-C alifatik ditunjukkan pada bilangan gelombang 2936,22 $\mathrm{cm}^{-1}$ untuk kontrol dan 2936,22 $\mathrm{cm}^{-1}$ untuk perlakuan terbaik. Gugus $\mathrm{C}=\mathrm{C}$ aromatic; $-\mathrm{CH}_{2} ; \quad-\mathrm{CH}_{3}$ deformation; C-O-C cincin heterotanin; -C-O stretching dan Para disubtituted sebagai ciri khas benzena (aromatik terkonjugasi) juga ditemukan pada kontrol dan perlakuan terbaik. Dengan adanya band-band tersebut menunjukkan bahwa hasil ekstrak diduga kuat terkandung tanin.

\section{KESIMPULAN DAN SARAN}

\section{Kesimpulan}

Perlakuan pendahuluan PEF (Pulsed Electric Field) dengan kombinasi frekuensi dan lama waktu PEF pada proses ekstraksi maserasi kinetik pada biji pinang segar tidak mempengaruhi rendemen, kadar tanin, kadar air dan aktivitas antioksidan ekstrak tanin. Frekuensi $1 \mathrm{kHz}$ dengan waktu paparan 20 detik sebagai perlakuan terbaik 
menghasilkan nilai rendemen 5,6\%; kadar air 7,78\%; nilai IC50 277,56 ppm; dan kadar tanin 442,36 mg $\mathrm{GAE} / \mathrm{g}$.

\section{Saran}

1. Perlu dimodifikasi kembali variasi waktu dan frekuensi pada perlakuan pendahuluan PEF.

2. Tegangan dan medan listrik pada PEF perlu diperbesar.
3. Perlu ditemukan kombinasi yang tepat agar terdapat pengaruh signifikan antar kedua faktor (waktu dan frekuensi) serta interaksinya

4. Diperlukan pengeringan bahan agar kandungan air berkurang.

\section{UCAPAN TERIMA KASIH}

Penelitian ini didukung oleh dana PNBP FTP UB sesuai SK Dekan FTP UB Nomor 74 Tahun 2017.

Tabel 1. Hasil band analisis FTIR tanin ekstrak terbaik (dalam satuan $\mathrm{cm}^{-1}$ )

\begin{tabular}{|c|c|c|c|c|c|}
\hline No. & Kontrol & $\begin{array}{l}\text { Ekstrak perlakuan } \\
\text { terbaik Frekuensi } 1 \\
\text { kHz; } 20 \text { detik }\end{array}$ & $\begin{array}{l}\text { Ekstrak tanin kulit pohon } \\
\text { Schinopsis quebracho } \\
\text { Colorado (Pantoja-Castro \& } \\
\text { Horacio, 2012) }\end{array}$ & $\begin{array}{l}\text { Nilai bilangan } \\
\text { gelombang }\left(\mathrm{cm}^{-}\right. \\
\text {1) }\end{array}$ & Jenis gugus fungsi \\
\hline 1. & $\begin{array}{l}3383,67 \\
3231,31\end{array}$ & 3264,09 & 3381 & $\begin{array}{l}3650-3590 \\
3200-3600\end{array}$ & $\begin{array}{l}\text {-OH (alkohol, } \\
\text { fenol) }\end{array}$ \\
\hline 2. & 2936,22 & 2936,22 & 2925 & $2960-2850$ & $\begin{array}{c}\text { C-H dan C-C } \\
\text { alifatik }\end{array}$ \\
\hline 3. & $\begin{array}{l}1609,28 \\
1522,49\end{array}$ & 1611,$21 ; 1522,49$ & 1614 & $1600-1500$ & $\mathrm{C}=\mathrm{C}$ aromatik \\
\hline 4. & 1443,42 & 1443,42 & 1452 & $1430-1470$ & $\begin{array}{l}-\mathrm{CH}_{2} ;-\mathrm{CH}_{3} \\
\text { deformation }\end{array}$ \\
\hline 5. & 1385,56 & 1379,77; & - & $1385-1355$ & $\begin{array}{l}\mathrm{C}-\mathrm{O}-\mathrm{C} \text { cincin } \\
\text { heterotanin }\end{array}$ \\
\hline 6. & 1063,47 & 1061,54 & 1165 & $1150-1040$ & -C-O stretching \\
\hline 7. & 822,38 & 824,31 & 646 & $840-790$ & $\begin{array}{c}\text { Para disubtituted } \\
\text { sebagai ciri khas } \\
\text { benzena (aromatik } \\
\text { terkonjugasi) } \\
\end{array}$ \\
\hline
\end{tabular}

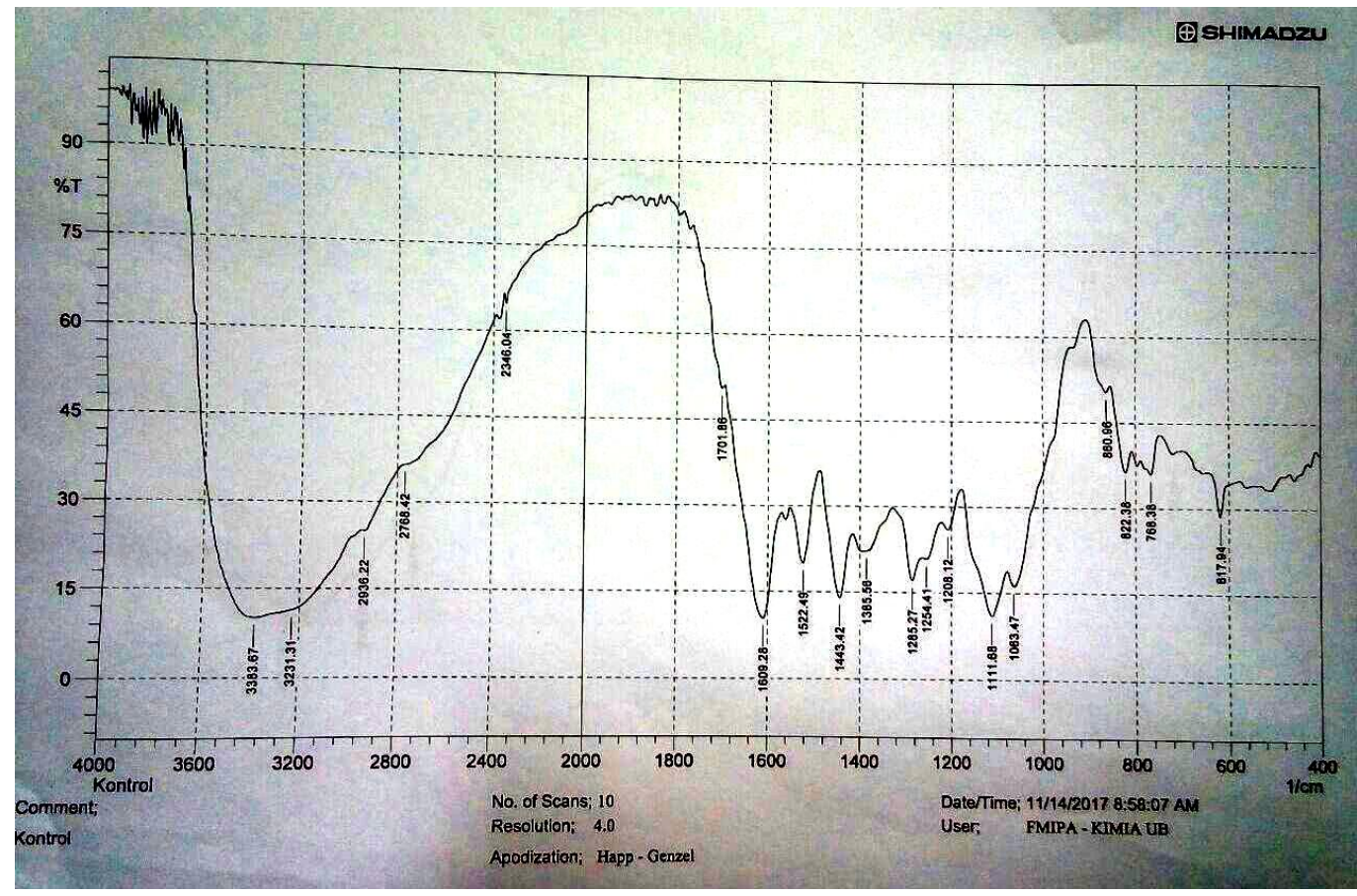

Gambar 6. Hasil spektra IR ekstrak tanin biji pinang (kontrol) 


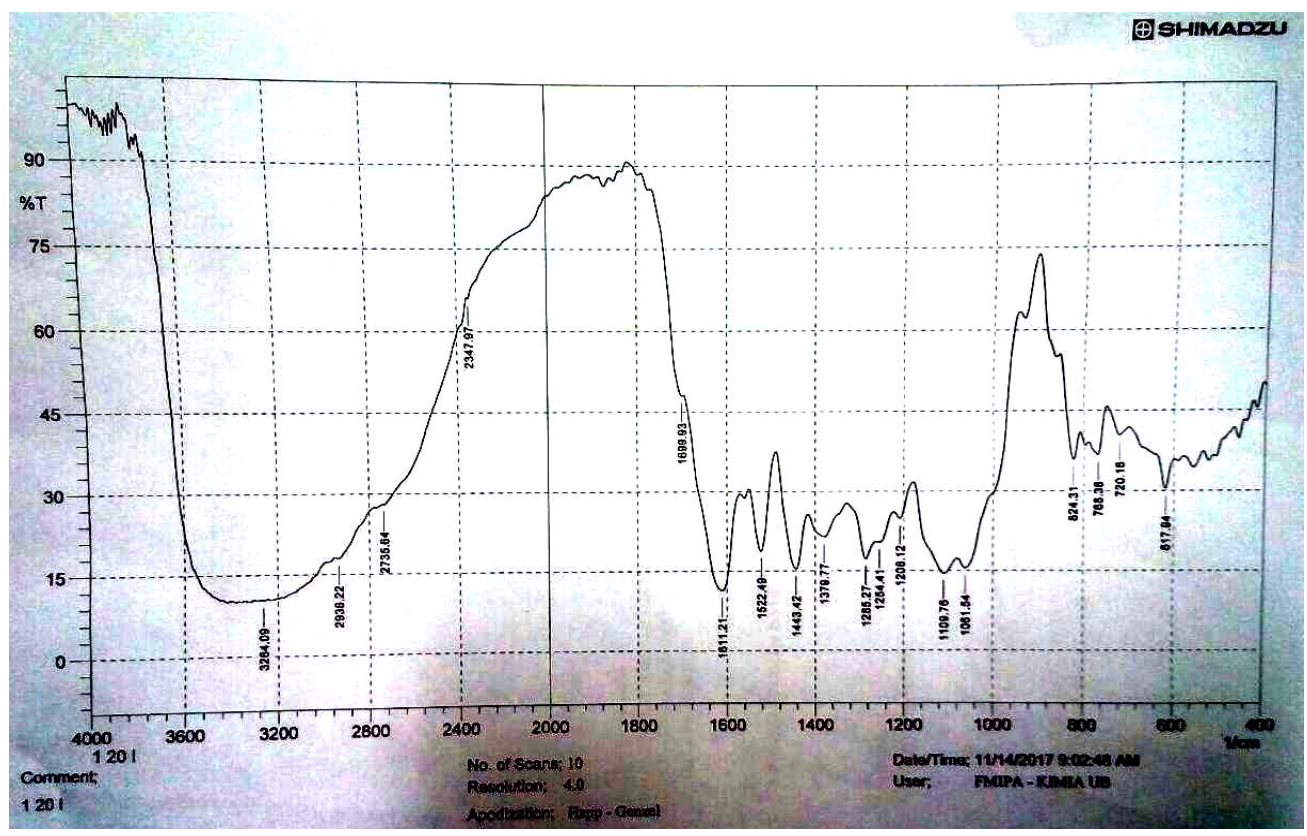

Gambar 7. Hasil spektra IR ekstrak tanin biji pinang (perlakuan terbaik)

\section{DAFTAR PUSTAKA}

Badan Pusat Statistik. 2017. Produksi perkebunan rakyat menurut jenis tanaman (ribu ton), 2000-2015.

https://www.bps.go.id/linkTabelStatis/view/i d/1670. [ 24 April 2017].

Bhandare AM, Ajay DK, Neeraj SV, Avinash AH, Vrushali ST. 2010. Potential analgesic, antiinflammatory and antioxidant activities of hydroalcoholic extract of Areca catechu L. nut. Food Chem Toxicol. 48: 3412-3417.

Donsi FG, Ferrari, dan Pataro G. 2010. Application of pulsed electric field treatments for the enhancement of mass transfer from vegetable tissue. Journal Food Eng Rev. 2 : 109-130.

Hamsar MN, Ismail S, Mordi MN, Ramanathan S, Mansor SM. 2011. Antioxidant activity and the effect of different parts of Areca catechu extraction glutathione-S-transferase activity in vitro. Free Radic Antioxid. 1 (1): 28-33.

Janositz A dan Knorr D. 2010. Microscopic visualization of pulsed electric field induced changes on plant cellular level. IFSET. 11: 592-597.

Jiahui L, Xinlao W, Yonghong W, Gongqiang L. 2009. Anlysisis for relationship of transmembrane potential pulse electric field frequency. Journal Food Bioprod Process. 87 (1): 261-265.

Jun M, Fuu HY, Hong J, Wan X, Yang CS, Cho CT. 2003. Comparison of antioxidant activities of isoflavones from kudzu root (Pueraria lobata Ohwi). Journal Food Science. 68(6): 2117-2122.

Mamonto SI, Max RJR, dan Frenly W. 2014. Aktivitas antioksidan ekstrak kulit biji buah pinang yaki (Areca vestiaria Giseke) yang diekstraksi secara soklet. Jurnal Ilmiah Farmasi. 3 (3): 268-272.

Peng W, Liu YJ, Wu N, Sun T, He XY, Gao YX, Wu CJ. 2015. Areca catechu L.(Arecaceae): a review of its traditional uses, botany, phytochemistry, pharmacology and toxicology. Journal Ethnopharmacol. 164: $340-356$.

Pliquet U. 2010. Bioimpedansi: a review for food processing. Journal Food Eng. 2: 74-94.

Rahmah NL, Sukardi, Beauty SDW, Wulandari HA. 2017. Effect of frequency and duration of pulsed electric field pre-treatment on antioxidant compounds extraction of dry areca nut (Areca catechu). Biotika. 5 (18): 6975.

Silva RS, Leonardo MR, Maria OM, Yule RFN, Paulo SNL. 2014. Seed structure and germination in buriti (Mauritia flexuosa), the Swamp palm. Flora. 209 :674-685.

Sukardi, Mahendra NN, Arie FM, Sucipto. 2016. Efek pulsed electric field (PEF) pada rendemen dan kualitas minyak bunga melati (Jasminum sambac) (kajian rasio bahan dan pelarut). Indonesian Journal Essential Oil. 1 (1): 30-43.

Sukardi. 2016. Elektroporasi membran sel untuk meningkatkan efisiensi distilasi minyak nilam. [Disertasi]. Malang: Universitas Brawijaya.

Tambe VD dan Rajendra SB. 2014. Estimation of total phenol, tannin, alkaloid and flavonoid in Hibiscus tiliaceus Linn. wood extracts. RRJPP. 2 (4): 41-47.

Yildiz F. 2010. Advances in Food Biochemistry. USA: CRC Press Taylor \& Francis Group. 